\title{
Cough receptor sensitivity in children with acute and non-acute asthma
}

\author{
Anne B Chang, Peter D Phelan, Colin F Robertson
}

\begin{abstract}
Background - Cough is a major symptom in some children with asthma. The relationship between cough and the severity of asthma is ill defined. A study was undertaken to test the hypotheses that, in children with asthma who cough as a major part of their asthma symptoms, cough receptor sensitivity (CRS) is heightened during an acute severe exacerbation of asthma but not in the non-acute phase and airway calibre or its change correlates with CRS. Methods-Spirometric measurements and the capsaicin CRS test were performed on children admitted to hospital for an acute severe exacerbation of asthma. Nasal secretions were tested for viruses. The children were grouped into those who usually cough with asthma episodes and those who do not. The tests were repeated 7-10 days and 4-6 weeks later. The CRS outcome measure used was the concentration of capsaicin required to stimulate two (Cth) and five coughs (C5).
\end{abstract}

Results - The CRS of the group who coughed $(n=15)$ was significantly higher than those who did not cough $(n=16)$ (mean difference log Cth $0.77 \mu \mathrm{mol}$ (95\% CI 0.35 to 1.18$)$, C5 $0.72 \mu \mathrm{mol}$ (95\% CI 0.26 to 1.18)) during acute asthma but not after the exacerbation. CRS was not significantly different between groups based on the presence of a viral infection. Neither forced expiratory volume in one second $\left(F_{1} V_{1}\right)$ nor its change correlated with CRS nor its change.

Conclusions - In children with asthma CRS is heightened in acute severe asthma in the subgroup of children who have cough as a significant symptom with their asthma episodes. In acute and non-acute asthma CRS does not correlate with $\mathrm{FEV}_{1}$. (Thorax 1997;52:770-774)

Keywords: cough, children, asthma.

Department of

Paediatrics,

University of

Melbourne

P D Phelan

Royal Children's Hospital,

Melbourne, Victoria

3052, Australia

Correspondence to: Dr A Chang.

Received 20 December 1996

Returned to authors

4 February 1997

Revised version received

17 June 1997

Accepted for publication

19 June 1997

Cough is a part of the symptom complex in some children with asthma but not in others. The relationship between cough and wheeze, and between cough and the severity of asthma, is poorly defined. Hoskyns and colleagues reported that, in children recovering from acute asthma, cough frequency did not correlate with clinical scores of severity of asthma nor with evening and morning peak flow or its variability. ${ }^{1}$ However, the presence of cough alone in children with asthma can be interpreted as a symptom of inadequately treated asthma. ${ }^{23}$
Cough receptor sensitivity (CRS) is increased in adults with cough-variant asthma ${ }^{4}$ but the relationship between the frequency of cough and CRS is unknown. The relationship between CRS and airway calibre is also unknown in those who cough as a major symptom of their asthma exacerbations. During the nonacute phase of asthma CRS is not increased ${ }^{5}$ and does not correlate with airway calibre changes induced in the laboratory by pharmacological challenges in either adults ${ }^{67}$ or children. ${ }^{8}$ However, the CRS of subjects during an acute phase of asthma has not been studied and laboratory induced bronchoconstriction is not identical to the bronchoconstriction that occurs in acute asthma exacerbations.

We have performed a study to test the hypotheses that, in children with asthma who cough as a major symptom, CRS is heightened during an acute severe exacerbation of asthma but not in the non-acute phase and airway calibre or its change correlates with CRS

\section{Methods}

SUBJECTS AND STUDY DESIGN

The study was conducted during two time periods (January to March and August to October 1996) to avoid the possibility of recruiting only subjects with a current respiratory tract infection during the winter months. Children aged more than six years who were admitted to the Royal Children's Hospital, Melbourne for an acute exacerbation of asthma were eligible for the study. Children with a chronic disease other than asthma (including a persistent cough for two weeks or more) were excluded. A clinical history was obtained; the parent(s) were asked to choose one of the two responses regarding the occurrence of cough with asthma symptoms - always/usually (coughers) or sometimes/with infections only/ never (non-coughers). The repeatability of the response was determined 1-2 months later in subjects enrolled during the second study period.

Clinical upper respiratory tract infection was considered present if the child had symptoms of nasal stuffiness, coryza, or throat irritation (with or without fever). ${ }^{9}$ A history of smoke exposure, medication use, and a functional severity score $(\mathrm{FSS})^{3}$ was also obtained. The FSS is a six item score based on the frequency of the symptoms $(0=$ none, $4=$ daily $)$ to a number of questions which includes nocturnal cough and exercise limitation. ${ }^{3}$ A category from 1 (low) to 4 (severe) was assigned from the sum of scores (range 0-24). The severity of the child's acute asthma episode on presentation 
Table 1 Clinical profile of the children with asthma who cough as a major component of their asthma episodes (coughers) and those who do not (non-coughers)

\begin{tabular}{|c|c|c|}
\hline & $\begin{array}{l}\text { Coughers } \\
(n=15)\end{array}$ & $\begin{array}{l}\text { Non-coughers } \\
(n=16)\end{array}$ \\
\hline $\operatorname{Sex}(M: F)$ & $7: 8$ & $8: 7$ \\
\hline Age (years), median (IQR) & $9(3.6)$ & $9(3.1)$ \\
\hline Smoke exposure, $\mathrm{n}(\%)$ & $6(40)$ & $5(31)$ \\
\hline Clinical URTI, n (\%) & $10(67)$ & $10(63)$ \\
\hline Virus identified, n (\%) & $2(13)$ & $1(6)$ \\
\hline Functional severity score, median (IQR) & $3(2)$ & $2.5(2)$ \\
\hline Nocturnal cough, median (IQR) & $2(1)$ & $1(2)$ \\
\hline Exercise limitation, median (IQR) & $2(2)$ & $1(1)$ \\
\hline Days before test, median (IQR)* & $1(1)$ & $1(1)$ \\
\hline Asthma severity score (1), median (IQR) $\dagger$ & $6(3)$ & $6(2)$ \\
\hline Asthma severity score (2), median (IQR) $\dagger$ & $2(1)$ & $2(2)$ \\
\hline $\mathrm{FEV}_{1} \%$ pred before capsaicin, median (IQR) & $87(20)$ & $79(30)$ \\
\hline $\mathrm{FEV}_{1} \%$ pred after capsaicin, median (IQR) & $86(28)$ & $84(39)$ \\
\hline Preventative therapy & $10(67)$ & $11(69)$ \\
\hline Inhaled steroids, n (\%) & $9(60)$ & $10(62)$ \\
\hline Oral steroids, $\mathrm{n}(\%)$ & $1(7)$ & $1(6)$ \\
\hline Cromoglycate, n (\%) & $3(20)$ & 1 (6) \\
\hline Theophylline, $\mathrm{n}(\%)$ & $1(7)$ & 0 \\
\hline
\end{tabular}

URTI $=$ upper respiratory tract infection; $\mathrm{FEV}_{1}=$ forced expiratory volume in one second; \% pred $=$ percentage predicted value.

$*$ Days before test $=$ days in hospital before tests were performed.

† Asthma severity score $(1)=$ score on admission; asthma severity score $(2)=$ score at time of testing.

The groups did not differ in any variable using the $\chi^{2}$ test.

and at the time of testing was graded on the asthma severity score (ASS), ${ }^{10}$ a scoring system based on the total score of three items (rhonchi, accessory muscle use, and heart rate), each scored 0-3.

Spirometric tests (Masterlab, Jaeger, Germany) were performed before and after the capsaicin CRS test on the day of, or the day before, discharge. Spirometric testing was performed in the upright seated position with a nose clip and the best of three attempts was recorded. The children were tested 30-60 minutes before the administration of their scheduled salbutamol nebulisation. Nasopharyngeal secretions were tested for the presence of viruses by immunofluorescence and culture during the acute admission. The specimens were processed by the virology laboratory in our hospital and cultured on three cell lines (human fibroblast $(\mathrm{HuFb})$, monkey kidney (LLC), and tumour (HeLa)). The tests (capsaicin CRS test, before and after spirometry) were repeated 7-10 days later and 4-6 weeks later in a subgroup of children.

Formal written consent was obtained and the study was approved by the hospital's ethics committee for human research.

\section{CAPSAICIN COUGH RECEPTOR SENSITIVITY (CRS)} TEST

We have previously described a method of performing the capsaicin CRS test in children that has good repeatability. ${ }^{11}$ Briefly, capsaicin (Sigma-Aldrich, Australia) diluted in $20 \%$ alcohol was delivered through a nebuliser controlled by a dosimeter (MB3, MEFAR, Italy) in an arrangement that allowed regulation of the inspiratory flow. The dosimeter was set at 0.7 seconds inhalation time and normal saline and diluent controls were given before doubling concentrations of capsaicin (1.23 to $1250 \mu \mathrm{mol}$ ) were inhaled. The number of coughs in the subsequent 30 seconds was counted by an independent observer. CRS measures were the lowest concentration of capsaicin required to stimulate two (Cth) and five coughs
(C5). In our laboratory the single determination $95 \%$ range for repeatability of this test (in log values) is 0.31 and 0.33 for Cth and $\mathrm{C} 5$, respectively (doubling dose difference 1.03 and 1.08 , respectively). ${ }^{11}$ CRS is considered to be heightened or increased when $\mathrm{Cth}$ and $\mathrm{C} 5$ values are lower.

STATISTICAL ANALYSIS

ASS and FSS values between groups were compared using the $\chi^{2}$ test. Normality of distribution was examined using Shapiro-Wilks statistics. Bonferroni method ${ }^{12}$ for multiple comparisons was used on log transformed data for comparisons between groups. As the distribution of the difference in CRS was not normal, paired Wilcoxon rank tests were utilised for comparing CRS measures during the acute and non-acute periods. Spearman's rank correlation $\left(r_{\mathrm{S}}\right)$ was used to correlate CRS and $\mathrm{FEV}_{1}$. A two-tailed $\mathrm{p}$ value of $<0.05$ was considered significant. Means (95\% CI) are expressed as mean (CI) of log transformed data unless otherwise specified. Repeatability of the question associating the child's cough with asthma episodes was determined using the Kappa ( $\kappa$ ) value. ${ }^{13} \mathrm{FEV}_{1}$ measurements are expressed as percentage predicted values.

\section{Results}

Thirty one children were recruited (15 during January to March and 16 during August to October). The clinical profile of the children is shown in table 1 . There was no significant difference between the groups in age, smoke exposure, clinical upper respiratory tract infections, use of preventative medications, FSS, frequency of nocturnal cough or exercise limitation, $\mathrm{FEV}_{1}$, or the severity of asthma on presentation (ASS) and at the time of testing. Twenty children $(64.5 \%)$ had clinical upper respiratory tract infection but a virus was identified in only three $(15 \%)$ of these children.

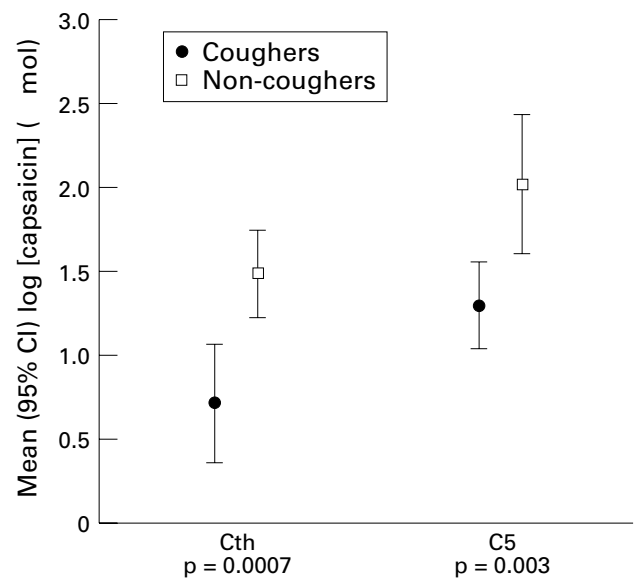

Figure 1 Comparison of cough receptor sensitivity during the acute asthma exacerbation between children with asthma who cough as a major symptom of their asthma episodes (coughers) and those who do not cough (noncoughers). Cth $=$ concentration of capsaicin required to stimulate two coughs; $C 5=$ concentration of capsaicin required to stimulate five coughs. 

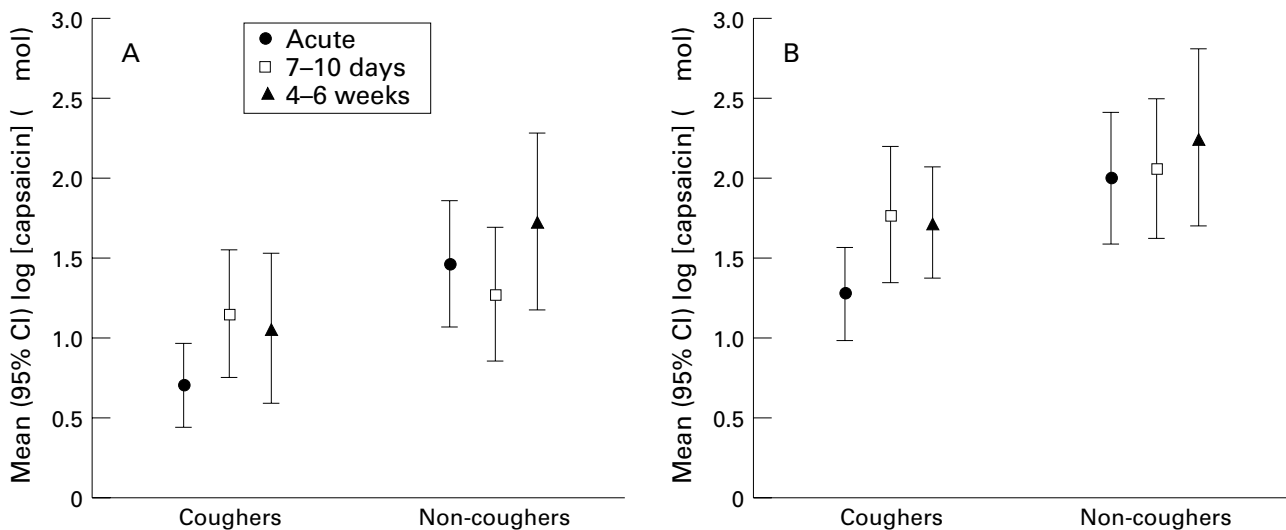

Figure 2 Comparison of $(A) C t h$ and $(B)$ C5 values during the acute asthma exacerbation, 7-10 days and 4-6 weeks following the acute asthma phase, between children with asthma who cough as a major part of their asthma episodes (coughers) and those who do not cough (non-coughers). Cth=concentration of capsaicin required to stimulate two coughs; $\mathrm{C5}=$ concentration of capsaicin required to stimulate five coughs. There was no significant difference between tests 2 and 3 in either group.

There was excellent agreement $(\kappa=0.75)$ between the reporting by parents of cough in association with asthma episodes on the two occasions.

During the acute episode Cth and C5 in the group who coughed were significantly lower (representing higher CRS) than in those without a cough (fig 1). The mean difference between the two groups was $0.77 \mu \mathrm{mol}(95 \% \mathrm{CI}$ 0.35 to 1.18 ) for Cth and $0.72 \mu \mathrm{mol}(95 \% \mathrm{CI}$ 0.26 to 1.18 ) for $\mathrm{C} 5$. When tested during the non acute phases $7-10$ days and $4-6$ weeks after the acute presentation there was no difference between the groups (fig 2). In the group that coughed the difference in CRS between the acute and non-acute episode (day 7-10) was significant (mean difference in Cth $0.49 \mu \mathrm{mol}$ ( $95 \%$ CI 0.13 to 0.85 ), $\mathrm{p}=0.01$; mean difference in C5 $0.52 \mathrm{~mol}$ (95\% CI 0.28 to 0.76 ), $\mathrm{p}=0.008)$. There was no significant difference between the two phases of asthma in the noncoughing group (mean difference in Cth $-0.10 \mu \mathrm{mol}(95 \% \mathrm{CI}-0.43$ to 0.23$)$ and in C5 $0.19 \mu \mathrm{mol}(95 \% \mathrm{CI}-0.10$ to 0.45$))$. CRS was not significantly different between the groups based on the presence of clinical or culture proven viral infection.

$\mathrm{FEV}_{1}$ did not change after capsaicin inhalation (table 1). CRS did not correlate with $\mathrm{FEV}_{1}$ in either the group that coughed $\left(r_{\mathrm{S}}=-0.08\right.$ for Cth; $r_{\mathrm{S}}=0.03$ for $\mathrm{C} 5$ ) or the group that did not cough $\left(r_{\mathrm{S}}=0.11\right.$ for Cth; $r_{\mathrm{S}}=-0.19$ for C5). The change in CRS between the acute (day 1) and non-acute (7-10 days later) phase for both groups did not correlate with the change in $\mathrm{FEV}_{1}$ between the two test days. The change in $\mathrm{FEV}_{1}$ between the acute and nonacute phase for the children who coughed was not significantly different from the children who did not cough (mean difference between coughers and non-coughers $=-18.5 \%(95 \%$ CI -43.3 to 6.2 ).

\section{Discussion}

This study has shown that, during an acute severe exacerbation of asthma, CRS is heightened in children with asthma who cough as a major symptom when compared with those who do not usually cough with their asthma exacerbations. Following the resolution of the acute asthma phase, this heightened CRS returns to a level similar to that of children with asthma who do not usually cough. We have also shown that there was no correlation between CRS and airway calibre as measured by $\mathrm{FEV}_{1}$ in either group.

The severity of the cough is not related to measures of airway calibre in subjects with asthma. ${ }^{114}$ However, in questionnaires cough alone is often used as a symptom of the stability of asthma. ${ }^{23}$ In children the frequency of nocturnal cough in the recovery phase of acute severe asthma does not correlate with the clinical severity of asthma, nor to airway calibre measured by peak flow in its absolute values or its variability. ${ }^{1} \mathrm{Hsu}$ and colleagues showed that, in adults with non-acute asthma, the frequency of cough measured objectively (with an ambulatory cough meter) had no relationship to asthma severity measured by $\mathrm{FEV}_{1}$ and diurnal peak flow variation. ${ }^{14}$ Could heightened CRS account for these patients with asthma who have troublesome coughing? Asthma in children is known to be a variable disorder and it has been questioned as to whether it is a single disorder or a whole variety of different pathological processes that result in a common feature which is airways obstruction that varies from time to time. ${ }^{15}$ The results of this study suggest that a subset of children with asthma develop heightened cough receptor sensitivity during acute exacerbations while others do not. This may be associated with the severity of the inflammation as the pathophysiology of coughing in asthma is likely to be related to the inflammatory process. ${ }^{16}{ }^{17}$ However, we did not measure any marker of inflammation and cannot substantiate this possibility. Fujimura et al recently showed that indomethacin and OKY-046 (a thromboxane synthesis inhibitor) significantly altered the capsaicin cough threshold in adults with asthma, but not in normal controls, and suggested that cyclooxygenase products alter CRS in inflammatory airway diseases. ${ }^{17}$ Another possible explanation why 
a subset of children with asthma develop a heightened CRS during an acute episode could be related to the different response of some individuals to a specific stimulus, similar to aspirin sensitivity in a subset of patients with asthma. ${ }^{18}$ Patients with aspirin-sensitive asthma are known to have a different response to aspirin, possibly from altered target organ sensitivity, which results in increased release of cysteinyl leukotrienes and eosinophil degradation..$^{18}$ In a recent editorial Hills suggested that, in the airways of patients with asthma, the breakdown of the natural physical barrier of surfactant - thus unmasking receptors - may contribute to the pathophysiology of asthma. ${ }^{19}$ Minor qualitative or quantitative deficiencies in surfactant could be present in children who cough with their asthma episodes. Surfactant deficiency has been shown in the upper airways of adults with asthma. ${ }^{19}$ Perhaps just as children with cystic fibrosis may have predominantly pulmonary or gastrointestinal complications (or both) which cannot be entirely explained by genotype difference, children with asthma may predominantly have cough or wheeze or both. All these explanations are, however, speculative and we do not have data to support them, but further research into why a subgroup of children with asthma are coughers would shed some light on the common paediatric problem of coughing.

Several groups have shown the independence of CRS and bronchomotor tone in the laboratory. $^{6-8}$ These studies were performed in adults ${ }^{67}$ and children ${ }^{8}$ with asthma who did not have acute asthma. In this study, performed in the true clinical situation of an acute asthma exacerbation, we also found that CRS does not correlate with $\mathrm{FEV}_{1}$. However, although spirometric tests and the capsaicin test were routinely performed $0.5-1$ hour before the scheduled salbutamol nebulisation, the frequency of the administration of salbutamol during the acute attack was variable, and therefore the generalisation of this finding is limited.

The repeatability of questions relating to cough in epidemiological studies is generally poor ${ }^{20}$ with $\kappa$ values as low as $0.19 .{ }^{21}$ However, when the question of cough was combined (cough and phlegm), the repeatability was very good $(\kappa=0.7) .^{20}$ It is not surprising that the repeatability of the question relating cough and asthma episodes was also excellent $(\kappa=0.75)$ since, not only was the question of cough specifically related to asthma episodes, but also the subjects in our study were a highly selected group, biased towards willing and knowledgeable parents of children with moderate to severe asthma.

A potential criticism of our study is the low virus identification rate $(15 \%)$ in our subjects. Nevertheless, this is comparable to a recent study in which a virus was identified by nasopharyngeal culture and/or serological testing in less than $10 \%$ of 300 adults who had a common cold. ${ }^{22}$ In a community study of children with a past history of bronchial hyperreactivity or persistent cough, virus was detected by the polymerase chain reaction (PCR) technique in $80 \%$ of those with an exacerbation of asthma. ${ }^{23}$ The subjects in our study, who were all admitted to hospital for their asthma with severe wheeze and dyspnoea, are considerably different from the children of that community study ${ }^{23}$ whose asthma exacerbations were identified by changes in peak expiratory flow, which has many pitfalls. ${ }^{24}$ Furthermore, the carriage rate of the virus type identified by PCR during the asymptomatic phase of that group of children was not reported..$^{23}$ The culture techniques of our laboratory cannot identify several viruses associated with the common cold - namely, coronavirus and reovirus. ${ }^{9}$ However, we believe that our low rate of viral identification did not alter our findings because (1) there was an equal number of clinical upper respiratory tract infections in each group (10 in each group), (2) when the children were grouped based on upper respiratory tract infection (present or absent) there was no significant difference in CRS between the two groups, and (3) the clinical diagnosis of upper respiratory tract infection was made prior to the knowledge of the viral studies and cough group.

We conclude that, in children with asthma, CRS is heightened during the acute severe phase in the subgroup of children who cough with their asthma episodes. CRS decreases to levels similar to children with asthma who do not have troublesome coughing within 7-10 days and does not correlate with $\mathrm{FEV}_{1}$. Altered sensitivity of cough receptors during an acute exacerbation may be a reason why some children with asthma cough. The relationship between coughing and asthma in children requires further investigation.

ABC is supported by the National Health and Medical Research Council (Australia).

1 Hoskyns EW, Heaton DM, Beardsmore CS, Simpson H. Asthma severity at night during recovery from an acut asthmatic attack. Arch Dis Child 1991;66:1204-8.

2 Isles A, Robertson CF. Treatment of asthma in children and adolescents: the need for a different approach. Med F Aust 1993;158:761-3.

3 Rosier MJ, Bishop J, Nolan T, Robertson CF, Carlin J, Phelan PD. Measurement of functional severity of asthma in children. Am f Respir Crit Care Med 1994;149:1434-41.

4 O'Connell F, Thomas VE, Pride NB, Fuller RW. Capsaicin cough sensitivity decreases with successful treatment of chronic cough. Am $\mathcal{F}$ Respir Crit Care Med 1994;150: chronic

5 Fujimura M, Sakamoto S, Kamio Y, Saito M, Miyake Y Yasui $M$, et al. Cough threshold to inhaled tartaric acid and bronchial responsiveness to methacholine in patient with asthma and sinobronchial syndrome. Intern Med 1992;31:17-21

6 Smith CA, Adamson DL, Choudry NB, Fuller RW. The effect of altering airway tone on the sensitivity of the cough reflex in normal volunteers. Eur Respir F 1991;4:1076-9.

7 Fujimura M, Sakamoto S, Kamio Y, Matsuda T. Effects of methacholine induced bronchoconstriction and procatero induced bronchodilation on cough receptor sensitivity to inhaled capsaicin and tartaric acid. Thorax 1992;47:441-5. 8 Shimuzu T, Mochizuki H, Tokuyama K, Morikawa A Relationship between acid-induced cough response and airway responsiveness and obstruction in children with asthma. Thorax 1996;51:284-7.

9 Cherry JD. Upper airway infections. In: Feigin RD, Cherry JD J . Textbook of pediatric infectious diseases. 3 rd JD, eds. Textbook of pediatric infectious diseas

10 Bishop J, Carlin J, Nolan T. Evaluation of the properties and reliability of a clinical severity scale for acute asthma

11 Chang AB, Phelan PD, Roberts RGD, Robertson CF. Capsaicin cough receptor sensitivity test in children. Eur Respir f 1996;9:2220-3

12 Altman DG. Practical statistics for medical research. London Chapman \& Hall, 1991: 210-1.

13 Altman DG. Practical statistics for medical research. London: Chapman \& Hall, 1991: 403-6.

14 Hsu JY, Stone RA, Logan-Sinclair RB, Worsdell M, Busst $\mathrm{CM}$, Chung KF. Coughing frequency in patients with 
persistent cough assessment using a 24 hour ambulatory recorder. Eur Respir F 1994;7:1246-53.

15 Phelan PD, Olinsky A, Oswald H. Asthma: classification, clinical patterns and natural history. In: Phelan PD, ed. Baillière's clinical paediatrics - asthma. London: Baillière Tindall, 1995: 307-18.

16 Barnes PJ. Effect of nedocromil on airway sensory nerves. 7 Allergy Clin Immunol 1993;92:182-6.

17 Fujimura M, Kamio Y, Kasahara K, Bando T, Hashimoto T, Matsuda T. Prostanoids and cough response to capsaicin in asthma and chronic bronchitis. Eur Respir F 1995; 8:1499-505.

18 Lane SJ, Lee TH. Mast cell effector mechanisms. f Allergy Clin Immunol 1996;98:S67-72.

19 Hills BA. Asthma: is there an airway receptor barrier. Thorax 1996;51:773-6.
20 Brunekreef B, Groot B, Rijcken B, Hoek G, Steenbekkers A, de Boer A. Reproducibility of childhood respiratory symptom questions. Eur Respir f 1992;5:930-5.

21 Luyt DK, Burton PR, Simpson H. Epidemiological study of wheeze, doctor diagnosed asthma and cough in preschoo children in Leicestershire. BMF 1993;306:1386-90.

22 Kaiser L, Lew D, Hirsel B, Auckenthaler R, Morabia A Heald A, et al. Effects of antibiotic treatment in the subset of common-cold patients who have bacteria in nasopharyngeal secretions. Lancet 1996;347:1507-10.

23 Johnston SL, Pattermore P, Sanderson G, Smoth S, Lampe $F$, Josephs $L$ et al. Community study of role of viral $F$, Josephs L, et al. Community study of role of vira infections in exacerbations of as
children. BMf 1995;310:1225-8.

24 Legge JS. Peak-expiratory-flow meters and asthma selfmanagement. Lancet 1996,347:1709-10. 